\title{
http://dx.doi.org/10.12795/RAA.2012.i02.05
}

\section{SELECCIÓN PATRIMONIAL: DEL CONSUMO COTIDIANO AL CONSUMO TURÍSTICO (ISLA DE FUERTEVENTURA, ISLAS CANARIAS)}

\author{
PABLO DÍAZ RODRÍGUEZ \\ Universidad Complutense de Madrid \\ AGUSTÍN SANTANA TALAVERA \\ Universidad de La Laguna \\ ALBERTO JONAY RODRÍGUEZ DARIAS
Universidad de La Laguna
}

\section{Resumen.}

La voluntad de reconversión y diferenciación de la isla de Fuerteventura (Islas Canarias, España) ante la presión del turismo de masas se refleja en una serie de procesos de patrimonialización enfocados a conseguir un modelo turístico que complemente el tradicional de sol y playa.

Esta reorientación turística, basada en un tipo de discurso patrimonialista y de la sostenibilidad, implica una resignificación del territorio que rara vez tiene en cuenta las diferentes lecturas generadas a partir de vivencias y prácticas cotidianas de las poblaciones locales. Estos cambios pueden tener efectos directos sobre las representaciones territoriales de sus habitantes y en consecuencia en la conformación del mismo.

Una forma de minimizar los impactos que se derivan de la resignificación territorial que implica la generación de imágenes culturales es basar la selección y resimbolización de 
los bienes que las configuran en las imágenes propias de las poblaciones locales.

Partiendo de la idea de que la percepción del entorno viene condicionada por los usos y prácticas presentes y las expectativas futuras, un primer paso para indagar sobre las posibles discordancias entre las poblaciones residentes y los consumidores exógenos a la hora de percibir el medio y sobre los procesos de implementación de estrategias de diferenciación del destino, puede ser la caracterización de las diversas prácticas realizadas por los principales grupos de usuarios en la isla.

Los resultados deberían ser un indicio importante de hasta qué punto tales discursos contemplan las perspectivas de las poblaciones locales respecto a su territorio a la hora de seleccionar y simbolizar espacios y actividades que les son propios. Para ello, en base a un análisis multivariante llevado a cabo a partir de los resultados de una encuesta realizada a turistas y nativos, y de los datos construidos a partir de un trabajo de campo etnográfico, en este trabajo se caracterizan las distintas percepciones en base a las actividades que unos y otros realizan con cierta regularidad en Fuerteventura.

Palabras clave: Poblaciones locales, reorientación turística, representaciones territoriales, resignificación, sostenibilidad, imagen proyectada.

\section{Abstract.}

The island of Fuerteventura (The Canary Islands, Spain) is moving towards recycling and differentiation of its tourist products on offer, focusing on Heritage, responding to mass tourism pressure and the need to complement the traditional Three ' $\mathrm{S}$ ' tourism.

This new move in tourism has been triggered by the need to move towards sustainability and implies a reinterpretation of the island territory that rarely takes into account the different meanings derived from the daily experiences and practices of the islanders. These changes will have a direct effect on the territorial representations of the population and thus on the spaces that they occupy.

One way of minimising the impacts deriving from a reinterpretation of the island around its culture is to use and reinvest with symbolism the cultural icons upon which the local populations reach consensus.

If we work on the idea that the perception of our environment is conditioned by our present uses and practices and future aspirations, the first step in researching the possible disagreements between the resident population and the foreign consumers in environmental perceptions and the processes to implement strategies of differentiation of the resort, may be using the characteristics of the various major practices of the main groups of residents on the island.

The results should indicate to what extent new discourses and interpretations contemplate the perspectives of the local populations with respect to their territory when selecting 
and symbolising the spaces and activities that are considered to be characteristic. A multivariable analysis of the results of a survey carried out among locals and tourists is used together with the qualitative data created in ethnographic fieldwork to characterise the different perceptions based on the habitual practices of both groups.

\section{Keywords:}

Local populations, tourism reorientation, territorial representation, reinterpretation, sustainability, projected image.

\section{INTRODUCCIÓN}

El final de la década de los ochenta y principio de los noventa suele establecerse como el periodo en el que comienzan a proliferar procesos de búsqueda y desarrollo de nuevos y diferenciados productos turísticos que pudieran ser aceptados (o encajados, según el caso) por la fuerte demanda de ocio occidental (Butler, 1994). Estos nuevos productos se caracterizan por (a) su orientación -aparentemente- minoritaria y dirigida hacia un mercado objetivo 'de calidad' (alusión retórica y creíble para referir el segmento con mayor poder adquisitivo en relación al turismo estandarizado en cada destino), (b) una proyección de mayor rentabilidad económica y (c) una presentación en la que los efectos de la venta de los anteriores productos de masas (aún en vigor) supuestamente no son patentes en la nueva oferta.

Estas dinámicas se corresponden con un contexto social de preocupación y crisis medioambiental, económica e ideológica que fomenta la aparición de ciertos movimientos de diferenciación e individualización. Circunstancias que tienen su reflejo convenientemente adaptado en el sistema turístico, dando lugar a lo que en la literatura científica se ha denominado el 'post-turista' (Selwyn, 1990; Jules-Rosette, 1994; Harkin, 1995; Pretes, 1995; Nuryanti, 1996; Wang, 1999; Galani-Moutafi, 2000; Tucker, 2001), diferenciado por su búsqueda de una eufemística sofisticación y calidad de servicios, con una demanda orientada hacia segmentos ocultos y poco explotados del mercado o simplemente hacia la ocupación de los intersticios no absorbidos por los turismos clásicos.

Estos emergentes procesos turísticos, junto con las modas y estilos de vida que los acompañan, implican la presentación de una serie de manifestaciones culturales caracterizadas por su atemporalidad, su aparente desvinculación espacial y asociación a grupos sociales más virtuales que reales. Ciertos bienes que dan cohesión y grandeza a un imaginario del pasado y la tradición, esos lugares, son desde entonces rescatados, preservados y custodiados, no tanto por su funcionalidad para las poblaciones locales, sino más bien por el mero monumentalismo-conservacionismo, aunque para ello deban limitarse sus usos, adornarse sus estilos y recrear sus historias. 
Múltiples investigaciones se han centrado en el análisis de estas formas turísticas versadas en los patrimonios y sus consecuencias (Cater and Lowman, 1994; Smith and Eadington, 1994; Chambers, 1997; Smith and Brent, 2001, entre otros). No obstante, la inercia del mercado, las innovaciones y combinaciones que los destinos desarrollan respecto a los productos turísticos, revelan una realidad más dinámica que las teorías y sus pretensiones. En términos generales, a la par que se dieron los acercamientos turísticos al patrimonio, las poblaciones pusieron su empeño en utilizar su patrimonio real o supuesto como motor de mejora de su nivel de vida. Y el patrimonio y el turismo iniciaron juntos y dependientes un recorrido hacia la singularización.

El tropiezo económico del último lustro ha puesto de manifiesto que no se realizaron los esfuerzos necesarios para prever los efectos no deseados de tal dependencia. En primer lugar, la sobre-implicación del sistema turístico en la gestión de la cultura (Hannerz, 1996), con el objetivo de fomentar en sus consumidores el sentimiento de experiencia inolvidable y única (Markwell, 2001), impulsó tanto la repetibilidad y estandarización, como la subordinación de la preservación al rédito económico. Si en consecuencia con lo primero se observan trazas de homogeneización cultural y baja diferenciación turística, por lo segundo el estancamiento y/o declive de los destinos proyecta sombras sobre la preservación de patrimonios.

En segundo lugar, una de las afecciones consecuentes de esta forma de producción y consumo turístico-patrimonial se da en los procesos de construcción de las identidades locales (Franklin \& Crang, 2001), que por su influencia en las dinámicas de creación y recreación de las identificaciones culturales afecta al sentido de pertenencia, pasado, lugar, cultura y posesión.

La clave, no única, de estos efectos debe buscarse en los desencuentros entre las imágenes turísticas proyectadas y aquellas propias de las poblaciones locales (Santana, 2009). Los intereses y orientaciones identitarias, políticas o educativas de la cultura y su condensación patrimonial no implica una correspondencia directa respecto a sus consumos turísticos. La principal diferencia va a radicar en la necesidad, en gran medida promovida por la imagen que se ha vendido del mismo, de recrearlo (estética o físicamente) y escenografiarlo. Las poblaciones receptoras traducirán sus cualidades en mercancías y espectáculos consumibles (Picard \& Wood, 1997) convertidos en recurso, producto, experiencia y resultado (Craik, 1997).

\section{APROXIMACIÓN AL CONTEXTO DE ESTUDIO}

Fuerteventura es la segunda isla más extensa del archipiélago canario, frente a la costa noroeste de África. Su condición desértica, sus paisajes volcánicos y la distribución dispersa de unos 80 núcleos de población, otorgan a la isla un aspecto de territorio relativamente desocupado. 
Su clima subtropical y extensas playas han facilitado su inclusión en el mercado turístico de sol y playa. En las últimas décadas (a partir de los años 70 del siglo XX), las actividades productivas tradicionales (ganadería caprina extensiva, pesca de bajura y cultivo) han perdido importancia relativa frente al desarrollo del turismo y la construcción asociada a él. Este proceso ha conllevado modificaciones relevantes en la estructura sociocultural de la isla (Ruiz-Labourdette et al, 2010).

Este desarrollo no se ha producido de manera homogénea en todo el territorio. Bajo determinados condicionantes físicos (terrenos más llanos y adecuados a la construcción frente a espacios escarpados, menor incidencia del viento, extensas playas frente a grandes acantilados, etc.), la costa de sotavento ha sufrido mayores adaptaciones e incluye las principales áreas de alojamiento e infraestructuras turísticas. Mientras, en el interior de la isla y la zona de barlovento, las implicaciones del desarrollo turístico son menos evidentes y pueden percibirse con mayor facilidad rastros de determinadas actividades productivas tradicionales así como un entorno, al menos aparentemente, poco modificado por la acción humana.

Estos diferentes ritmos de crecimiento turístico han generado dinámicas diferenciales entre los núcleos de población de la isla. Mientras los núcleos turísticos de sol y playa de sotavento se caracterizan por un alto volumen de población, servicios, viviendas modernas y población joven, exógena y con trabajos relacionados con el sistema turístico, en el resto de la isla se repiten las pautas habituales de las afecciones del éxodo rural (núcleos con poca población, envejecida, con estructuras del hogar, edificios y empleos tradicionales, etc.; Ruiz-Labourdette et al, 2010; Díaz Rodríguez et al, 2010a, 2010b).

A partir de la ralentización en el crecimiento del número de turistas que llegan a la isla, especialmente a partir del año 2008 (Rodríguez Darias et al, 2010), y con la intención de captar la atención de determinados nichos de demanda, las administraciones locales parecen haber iniciado una estrategia orientada a singularizar la oferta de sol y playa a través de la inclusión en la oferta de determinados atributos relacionados con la cultura y naturaleza de la isla (Rodríguez Darias et al, 2010).

Esto puede explicar el incremento de procesos de patrimonialización que en la actualidad está experimentando la isla de Fuerteventura. Varios espacios han sido inscritos bajo diferentes categorías de protección, recientemente toda la isla ha sido declarada Reserva de la Biosfera y se está llevando a cabo un estudio técnico con intención de declarar uno de los Parques Nacionales más extensos del Estado español. A su vez, el número de Bienes de Interés Cultural se ha incrementado considerablemente en los últimos años (Figura 1). 
Figura 1. Evolución de Bienes de Interés Cultural declarados en Fuerteventura (19502008).

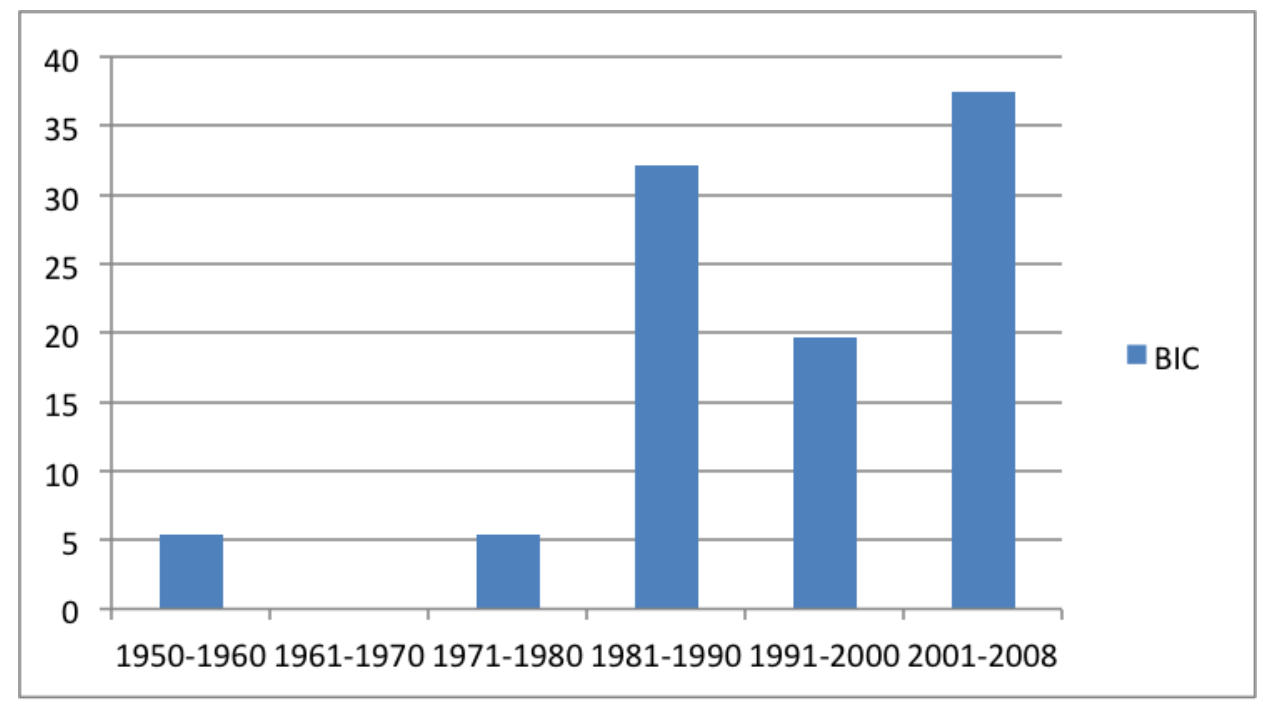

Fuente: Elaboración propia en base a datos del Gobierno de Canarias, Cabildo de Fuerteventura y ayuntamientos de la isla.

Esta estrategia de reorientación turística, basada en el discurso patrimonialista y de la sostenibilidad, implica una resignificación del territorio (generalmente a través de la exaltación de valores estéticos orientados al mercado) que puede derivar en confrontaciones con simbolizaciones formuladas y reformuladas por determinados grupos de población históricamente implicados con el territorio. Especialmente relevantes pueden ser los efectos sobre las representaciones territoriales de las poblaciones locales y, en consecuencia, la forma en que éstos se relacionan con su entorno (Franklin y Crang, 2001; Cánoves, Herrera y Villarino, 2005).

\section{DISCURSOS, PERCEPCIONES Y PRÁCTICAS}

En trabajos anteriores, se ha mostrado cómo los procesos de reorientación se hacen patentes en la selección de atributos utilizados por las administraciones locales para configurar la imagen proyectada de la isla (Rodríguez Darias et al, 2010; Santana et al, 2010b; Santana et al, 2010c). Como se refleja en la figura 2, determinados elementos patrimoniales han conseguido cierto protagonismo en materiales de promoción utilizados por las administraciones locales (en este caso folletos y páginas web). Al relacionar los contenidos expuestos con las prácticas turísticas o tipologías de turistas a las que se refieren estos medios (Figura 3), son aquellas ligadas a la cultura, en sentido anacrónico (museos, exposiciones, monumentos, etc.), hacia las que fundamentalmente se tiende a orientar. 
Figura 2. Elementos utilizados por las administraciones locales en las imágenes proyectadas a partir de folletos y páginas web.

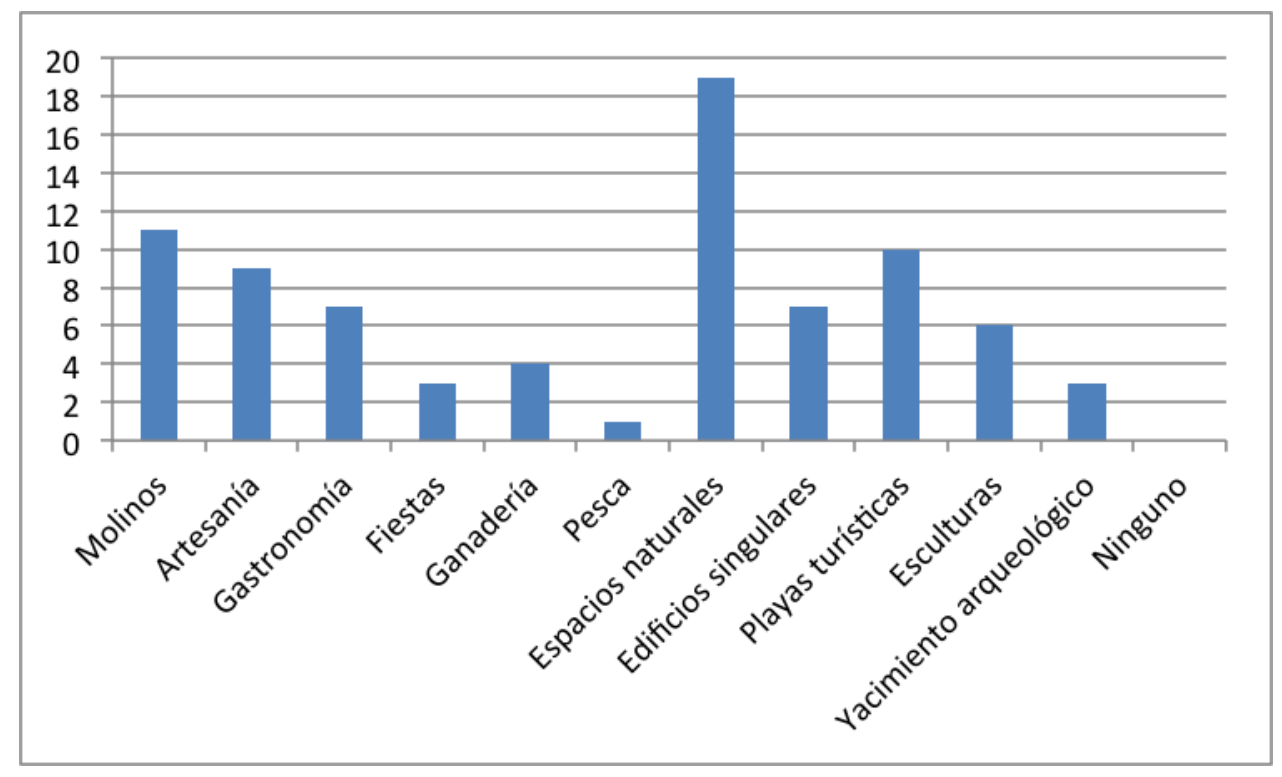

Fuente. Elaboración propia a partir de Rodríguez Darias et al, 2010.

Figura 3. Tipo de prácticas asociadas a las imágenes proyectadas por las administraciones locales.

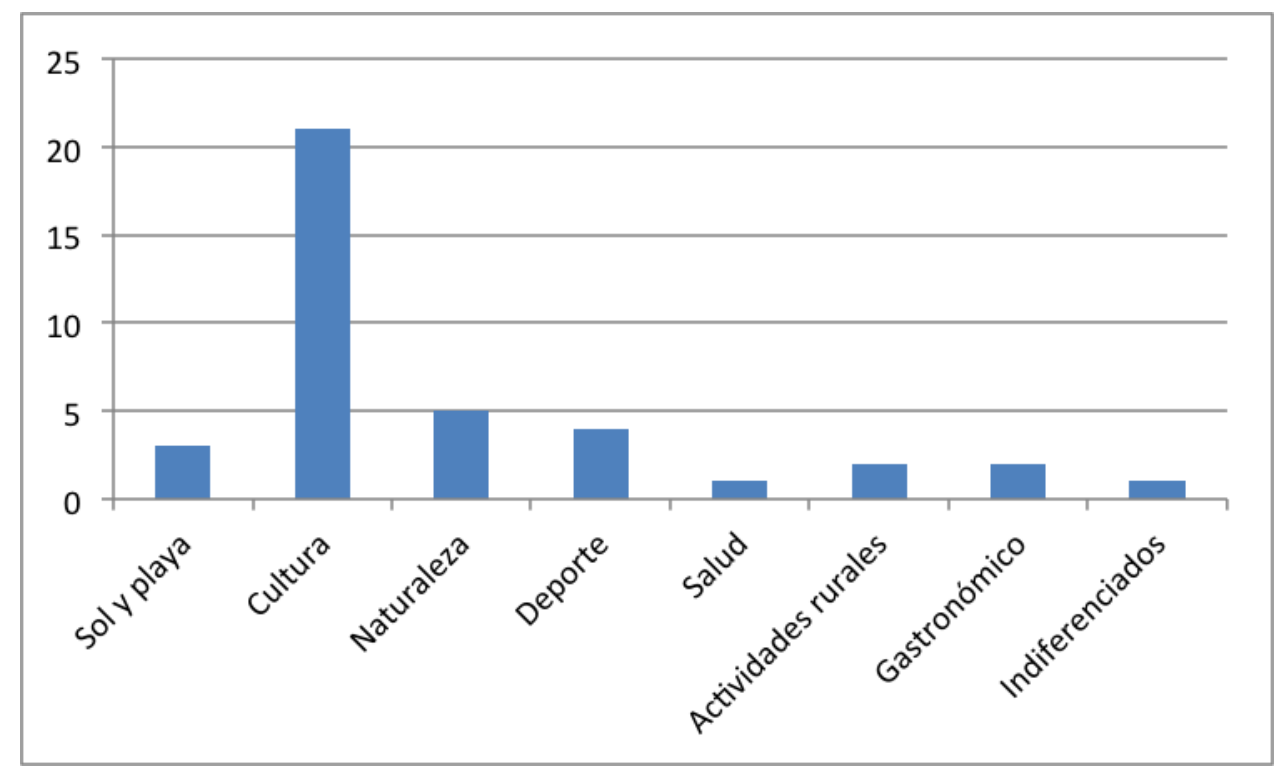

Fuente. Elaboración propia a partir de Rodríguez Darias et al, 2010. 
Estas modificaciones en la imagen proyectada, destinadas a complementar la oferta turística de sol y playa, así como a captar determinados nichos de demanda, implican la decidida incorporación a la oferta de determinados espacios que habían quedado relativamente marginados. Esto puede conllevar determinadas modificaciones en los paisajes, fruto de la modificación de prácticas y las alteraciones simbólicas que puedan derivarse de ello. Las nuevas imágenes propuestas pueden colisionar con las lógicas locales y derivar en conflictos de apropiación y diferentes estrategias de resistencia que podrían hacer incluso inviables las nuevas estrategias de reconversión.

Una forma de minimizar los impactos socioecológicos que se derivan de la resignificación territorial que implica la incorporación de estos espacios al relato turístico es basar los procesos de selección y resimbolización de los bienes en las imágenes propias de las poblaciones locales, esto es, la manera que tienen de concebirse a sí mismos y a su entorno (Santana, 2009), las cuales son generadas culturalmente y apropiadas en función de prácticas y experiencias personales (Valcuende del Río, 2004).

Partiendo de la idea de que la percepción del entorno viene condicionada por los usos y prácticas presentes y las expectativas futuras (Bell, 2001), un primer paso para indagar sobre las posibles discordancias entre las maneras de percibir el medio, por parte de las poblaciones residentes y los consumidores exógenos, y la implementación de estrategias de diferenciación del destino, puede ser la caracterización de las diversas prácticas realizadas por los principales grupos de usuarios en Fuerteventura.

Los resultados podrían ser un importante indicio de hasta qué punto el discurso patrimonialista actual contempla las perspectivas de las poblaciones locales respecto a su territorio a la hora de seleccionar y simbolizar espacios y actividades que les son propios. Para ello, en base a los resultados de una encuesta realizada a turistas y nativos trataremos de caracterizar las distintas percepciones en base a las actividades que unos y otros realizan con cierta regularidad en Fuerteventura.

\section{METODOLOGÍA}

El trabajo se basa en el análisis de una encuesta realizada sobre la práctica habitual de actividades en la isla. El cuestionario se llevó a cabo en cuatro oleadas a los dos grupos principales de usuarios del territorio de Fuerteventura, la población nativa y los turistas (Tabla 1). Los resultados fueron contrastados con los datos creados a partir de un trabajo de campo de carácter etnográfico desarrollado intermitentemente de 2008 a 2010. 
Tabla 1. Ficha de encuesta

\begin{tabular}{|l|c|c|}
\hline \multicolumn{1}{|c|}{ Muestra inicial por oleada } & NATIVOS & TURISTAS \\
\hline $\begin{array}{l}\text { Número de encuestas váli- } \\
\text { das (por oleada) }\end{array}$ & $98 / 87 / 83 / 246$ & 300 \\
\hline $\begin{array}{l}\text { Número total de encuestas } \\
\text { válidas }\end{array}$ & 514 & $319 / 308 / 312 / 353$ \\
\hline Fechas (por oleada) & $29-17$ Julio, 2009 & 1292 \\
\hline $\begin{array}{l}\text { 24 Septiembre-15 Octubre, } \\
2009\end{array}$ & $\begin{array}{c}\text { 29 Septiembre-4 Octubre, } \\
2009\end{array}$ \\
\hline $\begin{array}{l}\text { Sistema de recogida de } \\
\text { datos }\end{array}$ & $\begin{array}{c}\text { 29-28 Enero, 2010 } \\
\text { CATz-11-17 Enero, 2010 }\end{array}$ \\
\hline Lugares & 26-31 Marzo, 2010 \\
\hline $\begin{array}{l}\text { Método de selección de la } \\
\text { muestra }\end{array}$ & $\begin{array}{c}\text { Mistribución proporcional por } \\
\text { municipio }\end{array}$ & $\begin{array}{c}\text { Aeropuerto de Fuerteven- } \\
\text { tura }\end{array}$ \\
\hline
\end{tabular}

El estudio se realizó a partir de un análisis multivariante que permitió ordenar los usuarios de Fuerteventura encuestados en función de las prácticas que habitualmente realizan. Para ello se llevó a cabo un análisis de correspondencias múltiples (ACM) en diferentes fases. Una primera en la que se incluyeron todos los agentes encuestados sin diferenciación de categorías, lo que permitió distinguir a nivel general las diferentes formas de interactuar con el territorio, y una segunda en la que se realizó el mismo análisis de ordenación distinguiendo entre el grupo de nativos y el de turistas, con el objetivo de comparar ambos grupos en función de las formas en las que cada colectivo se ordena a partir de la realización o no de las actividades contempladas. La interpretación de los ejes resultantes se realizó a partir de los registros de observación y las entrevistas realizadas durante el periodo de campo.

\section{RESULTADOS}

Un primer paso consistió en la comparación general de la frecuencia de cada grupo respecto a la realización de las actividades consideradas en la encuesta. Los resultados mostraron que, si bien las principales diferencias de los actores locales frente a los visitantes se correspondían con la realización de prácticas tradicionales (participación y observación de fiestas tradicionales, camping, caza, pesca o deportes tradicionales), 
también es destacable el protagonismo frente a los turistas de actividades como la asistencia a museos, espectáculos o ciclos culturales y conferencias (Figura 4). Estas últimas, si bien en un principio solían ir dirigidas desde la Red de Museos del Cabildo a captar al consumidor exógeno, en los últimos años la estrategia de mejora de afluencia se ha extendido hacia el fomento del acceso de la población local:

“...el primer problema se solucionó cerrando acuerdos y precios con las agencia de viajes que representan a tourperadores, y el segundo a través de distintas iniciativas dirigidas a los residentes como por ejemplo la campaña de visitas escolares" (C. Umpierrez, consejera de la Red de Museos del Cabildo de Fuerteventura: http://www.fuerteventuradiario. $\mathrm{com} /$ ?p=9874)

Esto podría hacer pensar en la existencia de dos grupos diferenciados de pobladores autóctonos en función de sus prácticas habituales sobre el territorio, lo que, dado el caso, se correspondería en gran medida con los aspectos socioculturales diferenciales que caracterizan a los núcleos de población de Fuerteventura en función del ritmo de crecimiento de influencia turística (Díaz Rodríguez et al, 2010b). Esta circunstancia ha sido corroborada a nivel de trabajo de campo mediante observación participante, donde se constató que, si bien las actividades más tradicionales suelen ser practicadas en gran medida tanto en los núcleos más ruralizados como en los más turistizados, en los primeros suelen ser más cotidianas. Del mismo modo, en las entidades más turísticas la oferta de productos culturales del tipo de espectáculos, museos y exposiciones o ciclos culturales suele ser ampliamente aprovechada por los residentes locales.

Figura 4. Regularidad en la práctica de actividades por locales y turistas.

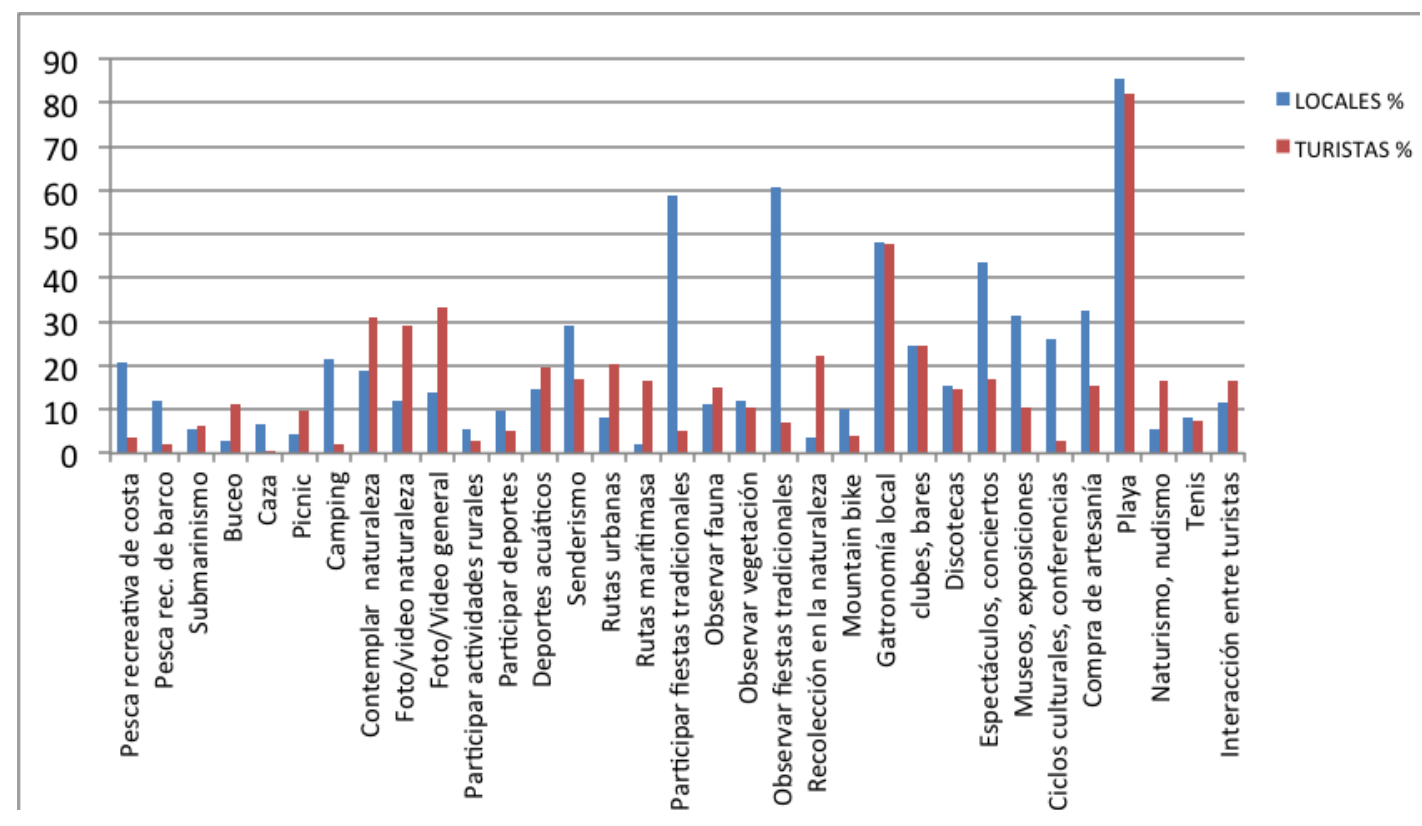

Fuente. Elaboración propia. 
Para realizar un análisis más detallado sobre la forma en que ambos tipos de usuarios se ordenan conjuntamente, en función de la práctica o no de las actividades consideradas, se realizó un ACM tomando como observaciones a todos los individuos a los que se realizó la encuesta, sin diferenciarlos por categorías a priori, y como variables las principales actividades realizadas en la isla detectadas a partir de un trabajo de campo de carácter etnográfico (presentes en la Figura 4).

Los dos primeros ejes resultantes del análisis (Tabla 2) mostraron diferentes formas en las que se ordena la población encuestada en función de las actividades que realizan o no. Tomando el primer eje, podría decirse que una forma de ordenar la población es a partir de la regularidad en la práctica de las actividades propuestas. Así, mientras las actividades más directamente relacionadas con el turismo climático (ir a la playa, hacer rutas marítimas, hacer nudismo, buceo, ir a restaurantes locales, hacer fotos y videos o interaccionar con los turistas) son realizadas con gran regularidad por locales y turistas, aquellas más directamente tradicionales (pesca, deportes tradicionales, camping, caza o participación en actividades rurales) y las vinculadas a actos más culturales desde el punto de vista instructivo, y más potenciadas desde las administraciones locales, como la asistencia a ciclos culturales, conferencias o la visita de museos y exposiciones, son realizadas con menor frecuencia por el grupo en general.

Tabla 2. Pesos de las variables sobre las principales actividades realizadas en Fuerteventura en los dos primeros ejes del análisis de ordenación hecho con el conjunto de población estudiado (locales y turistas). Del conjunto de 33 variables se representan sólo las de mayores pesos positivos y negativos.

\begin{tabular}{|l|c|l|c|}
\hline \multicolumn{1}{|c|}{ VARIABLE } & F1 & \multicolumn{1}{c|}{ VARIABLE } & F2 \\
\hline $\begin{array}{l}\text { Pesca recreativa de } \\
\text { barco }\end{array}$ & 1,653 & Recolección en la naturaleza & 1,323 \\
\hline $\begin{array}{l}\text { Ciclos culturales, } \\
\text { conferencias }\end{array}$ & 1,426 & Observación de la fauna & 1,247 \\
\hline $\begin{array}{l}\text { Participación en } \\
\text { deportes tradicionales }\end{array}$ & 1,159 & Foto/video de la naturaleza & 1,145 \\
\hline Camping & 1,117 & Observación de la vegetación & 1,113 \\
\hline Caza & 1,116 & Picnic & 0,995 \\
\hline Museos, exposiciones & 1,073 & Contemplación de la naturaleza & 0,979 \\
\hline Picnic & 1,063 & Ruta urbana & 0,966 \\
\hline $\begin{array}{l}\text { Participación en } \\
\text { actividades rurales }\end{array}$ & 1,039 & Foto, video en general & 0,955 \\
\hline \multicolumn{2}{|c|}{$* * *$} & & \multicolumn{2}{|c}{$* *$} \\
\hline
\end{tabular}




\begin{tabular}{|l|l|l|c|}
\hline Interacción con turistas & 0,609 & Espectáculos, conciertos & $-0,449$ \\
\hline Foto, video en general & 0,541 & Pesca recreativa de barco & $-0,623$ \\
\hline Gastronomía local & 0,418 & Observación de fiestas tradicionales & $-0,633$ \\
\hline Buceo & 0,360 & Participación en fiestas tradicionales & $-0,675$ \\
\hline Naturismo, nudismo & 0,342 & Ciclos culturales, conferencias & $-0,693$ \\
\hline $\begin{array}{l}\text { Recolección en la } \\
\text { naturaleza }\end{array}$ & 0,266 & Pesca recreativa de costa & $-0,752$ \\
\hline Ruta marina & 0,225 & Caza & $-0,762$ \\
\hline Playa & 0,142 & Camping & $-0,858$ \\
\hline F1 (12,95 absorbed variance) & \multicolumn{2}{|c|}{ F2 (21,91 absorbed variance) } \\
\hline
\end{tabular}

Este hecho puede corresponderse con la trayectoria que ha caracterizado a la isla desde los inicios de su desarrollo turístico: fomento de un turismo de sol y playa en la costa de sotavento y concepción del interior y barlovento como complemento (Rodríguez Darias et al, 2010). En los últimos años el fomento de estos complementos por parte de las administraciones locales ha sido particularmente patente, con una voluntad de potenciarlos y diversificar la oferta a partir de la protección ambiental y la activación patrimonial:

"El proyecto, en el plano cultural posibilitará hacer llegar a todos aquellos que estén en la Isla sus singularidades. En el ámbito económico, contribuirá a posicionar a Fuerteventura 'como un mercado de características singulares que no sólo oferte sol y playa sino toda una gama de parques naturales, bienes patrimoniales, zonas rurales y centros de ocio y museos" (C. Umpierrez, consejera de la Red de Museos del Cabildo de Fuerteventura: http://www. fuerteventuradiario.com/? $\mathrm{p}=8035$ )

El resultado de este análisis general muestra que las actividades que podrían concebirse como más orientadas al consumo turístico son realizadas con la misma regularidad por las poblaciones locales. Observando el plano de ordenación resultante del cruce de los dos primeros ejes del ACM (Figura 4), puede percibirse con más claridad cómo, si bien existe una gran heterogeneidad, ambos grupos tienden a realizar más frecuentemente las actividades más vinculadas al turismo de sol y playa y en menor medida, pero también, aquellas que han sido concebidas como complementarias (relacionadas con la tradición y la cultura). Podría decirse, en todo caso, como cabría esperar, que las poblaciones locales realizan en mayor medida que los turistas aquellas actividades más tradicionales productivas y de ocio previas al desarrollo turístico y hoy convivientes con él.

El plano realizado con el conjunto de agentes locales y turistas representa cómo se ordena cada observación teniendo en cuenta los usos que se realizan por el resto, sin diferenciar si se trata de un local o un turista, por lo que influye a la vez tanto las actividades realizadas 
en cada grupo como entre grupos. El gráfico, por lo tanto, mostraría las actividades que, en general, se realizan en la isla (Figura 4). La identificación de cada observación como local o turista en el gráfico se ha realizado a posteriori.

Otra forma de ordenar el conjunto de locales y turistas en función de las actividades realizadas es mostrada por el segundo eje del ACM (Tabla 2). En este caso, los pesos de las variables indican que existen dos tipos diferenciados de actores en función del tipo de prácticas realizadas. Por un lado, existen aquellas personas que realizan en mayor medida actividades relacionadas con aspectos vinculados a la naturaleza y el medio ambiente (recolección en la naturaleza, observación de fauna, foto y video de la naturaleza, observación de la vegetación o contemplación de la naturaleza), y por otro, las que prefieren realizar actividades más relacionadas con la tradición y la cultura. Estos resultados mostrarían que está habiendo un uso efectivo de las actividades complementarias que se están fomentando desde las administraciones. Además, si observamos el plano de ordenación (Figura 5) puede apreciarse cómo la población turista tiende más a realizar actividades relacionadas con el medioambiente, lo que encajaría con el reciente discurso sobre la sostenibilidad que desde las administraciones locales se está fomentando. En contra, la población nativa realiza en mucha mayor medida prácticas más vinculadas a la tradición y la cultura autóctona, y más concretamente con las actividades tradicionales de ocio, lo que además de responder a una lógica cultural nativa, concuerda con el reciente discurso patrimonialista.

Figura 5. Plano ACM. Muestra la posición de los agentes locales y turistas en función de las tendencias de variación.

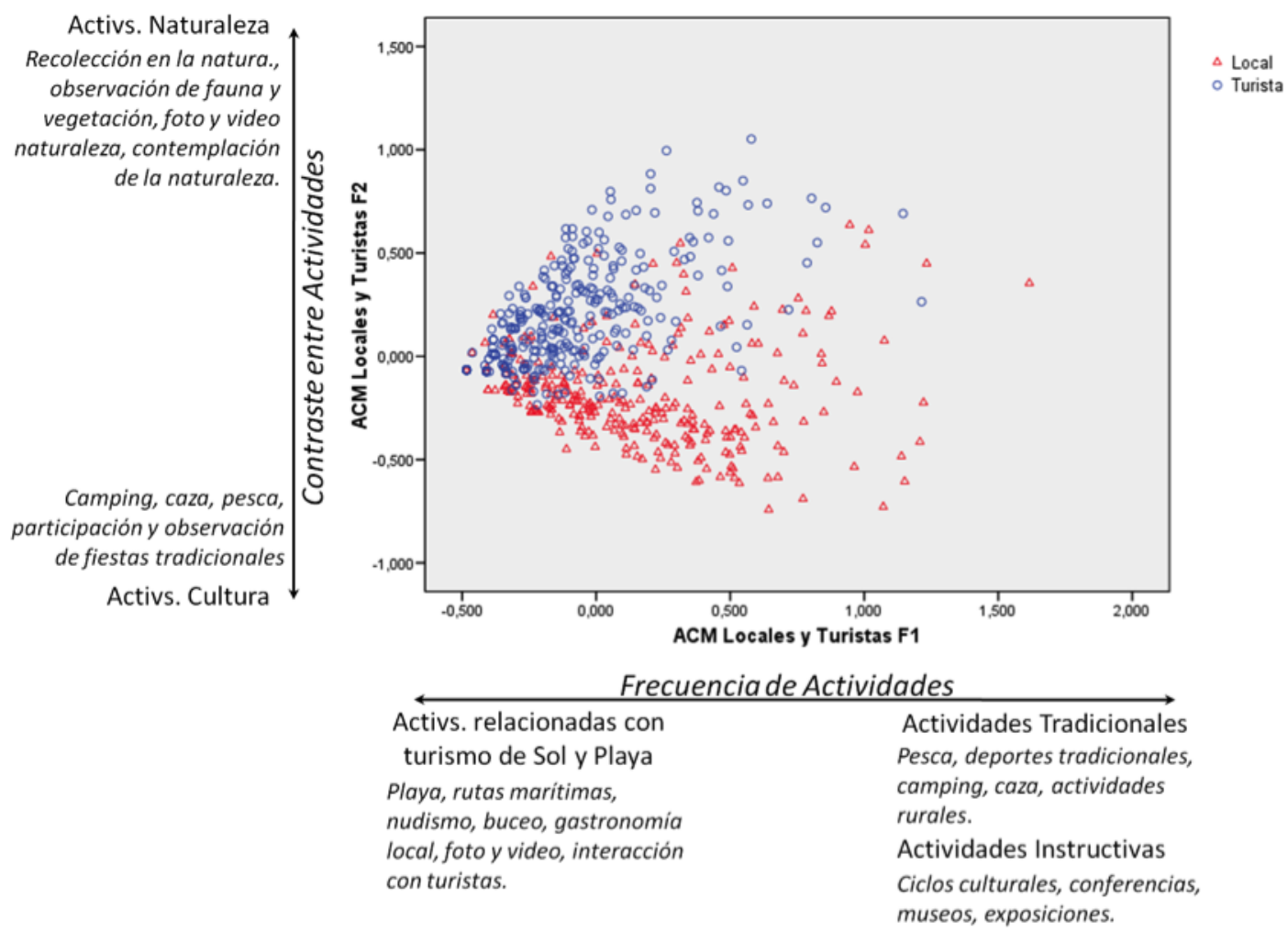


Para observar en detalle cómo se caracteriza cada grupo por separado en función de las prácticas que realizan sobre el territorio, se llevaron a cabo sendos ACMs individualizados. El resultado mostrará cómo se ordena cada grupo de manera exclusiva, en función de su procedencia (local o visitante) y sin que las actividades que hacen los individuos de un conjunto influyan en el otro, como ocurría en el ACM general. Es decir, una vez que hemos visto qué tipo de prácticas se realizan en general en la isla, pasamos a saber específicamente cuáles son las que realizan los locales y cuáles los visitantes.

Los dos primeros ejes resultantes del ACM realizado teniendo en cuenta al conjunto de visitantes como las observaciones, mostraron que las diferentes maneras en que éstos se ordenan tienen coherencia con lo apuntado respecto al grupo indiferenciado. Así, el primer eje muestra que, en primer lugar, la población visitante se ordena en función de la frecuencia general de las actividades practicadas. Esta frecuencia es muy similar a la que caracterizaba al primer eje del análisis de ordenación de la población en general, obteniendo que las actividades más frecuentes entre los turistas son aquellas más relacionadas con el turismo de sol y playa (playa, buceo, rutas marinas, tenis, gastronomía local, clubes y bares, etc.), mientras que las menos frecuentes son las prácticas que tienen más que ver con el turismo más cultural (observación de vegetación y fauna, rutas urbanas y senderismo, museos y exposiciones, etc.) (Eje 1, Tabla 3). Esto corrobora que a pesar del cambio de imagen que las administraciones locales están tratando de generar, el turismo de sol y playa sigue siendo la principal motivación de los turistas que acuden a la isla, quienes conciben el resto de la isla y sus posibilidades como alternativa en caso de no poder o no querer productos de sol y playa, o en todo caso como complemento a la hora de decidirse por el destino.

Tabla 3. Pesos de las variables sobre las principales actividades realizadas en Fuerteventura en los dos primeros ejes del análisis de ordenación hecho con el grupo de turistas. Se representan sólo las variables de mayores pesos positivos y negativos.

\begin{tabular}{|l|c|l|c|}
\hline \multicolumn{1}{|c|}{ VARIABLE } & F1 & \multicolumn{1}{c|}{ VARIABLE } & F2 \\
\hline $\begin{array}{l}\text { Observación de } \\
\text { vegetación }\end{array}$ & 1,664 & Discotecas & 1,375 \\
\hline Observación fauna & 1,327 & $\begin{array}{l}\text { Interacción con } \\
\text { turistas }\end{array}$ & 1,118 \\
\hline Rutas urbanas & 1,166 & $\begin{array}{l}\text { Clubes nocturnos y } \\
\text { bares }\end{array}$ & 1,089 \\
\hline Senderismo & 1,059 & $\begin{array}{l}\text { Espectáculos, } \\
\text { conciertos }\end{array}$ & 0,847 \\
\hline Picnic & 1,057 & Picnic & 0,744 \\
\hline Museos, exposiciones & 1,009 & Ruta marina & 0,601 \\
\hline
\end{tabular}




\begin{tabular}{|l|c|l|c|}
\hline \multicolumn{2}{|c|}{$* * *$} & \multicolumn{2}{c|}{$* * *$} \\
\hline Clubes nocturnos, bares & 0,539 & Foto, video en general & $-0,315$ \\
\hline Gastronomía local & 0,483 & Contempl. naturaleza & $-0,345$ \\
\hline Tenis & 0,427 & Ruta urbana & $-0,348$ \\
\hline Ruta marítima & 0,380 & Foto, video naturaleza & $-0,387$ \\
\hline Buceo & 0,254 & Senderismo & $-0,783$ \\
\hline Playa & 0,124 & $\begin{array}{l}\text { Recolecc. en la } \\
\text { naturaleza }\end{array}$ & $-0,833$ \\
\hline \multicolumn{2}{|c|}{ F1 (15,40 absorbed variance) } & \multicolumn{3}{|c|}{ F2 (8,43 absorbed variance) } \\
\hline
\end{tabular}

El segundo eje nos muestra otra forma de ordenación de la población turista acorde a las ya contempladas, aunque con ciertas peculiaridades. Desde esta perspectiva encontramos que existen dos tipos de visitantes diferenciados en función de la vinculación de las actividades al medio. Mientras que por un lado existe un tipo de visitante que realiza prácticas que implican una fuerte vinculación con el medio (recolección en la naturaleza, senderismo, foto y video de la naturaleza, rutas urbanas o contemplación de la naturaleza; parte negativa del Eje 2, Tabla 3), por el otro hallamos a aquellos cuyas actividades están más vinculadas a un ocio lúdico que podría entenderse desvinculado del entorno, en el sentido de que son actividades turísticas estándar que pueden realizarse independientemente del lugar, como ir a discotecas, clubes nocturnos, bares donde interaccionar con otras personas o asistir a espectáculos y conciertos (parte positiva del Eje 2, Tabla 3).

Por último, se realizó el mismo tipo de análisis con las poblaciones locales para comparar sus prácticas con aquellas de los turistas de manera individual. El resultado, partiendo de la idea de que la percepción del territorio viene influida por las prácticas en una relación dialéctica, podría servir de indicador sobre su concordancia con los nuevos discursos que vienen implantándose en la isla en los últimos años.

De nuevo, los dos primeros ejes del ACM nos muestran diferentes maneras en que las poblaciones locales de la isla pueden ser ordenadas en función de sus prácticas. A diferencia del grupo de visitantes, estos actores realizan este tipo de actividades ociosas de manera cotidiana en un territorio que les es propio y con el que mantienen una apropiación más allá de la temporal, característica de las poblaciones turistas. Además, estas poblaciones han convivido de manera prolongada con un discurso de rentabilización del territorio que ha ido generando poco a poco imágenes y productos adecuados fundamentalmente al consumidor exógeno, configurándose como opciones que han ido incorporándose como alternativas o complementarias al ocio habitual entre ciertas poblaciones autóctonas. Este hecho puede apreciarse en las diferentes formas en que se ordena la población local según los resultados creados, donde puede apreciarse 
una tendencia a la realización de prácticas tradicionales aderezada con características más típicamente turísticas. Esto podría responder a su vez a la diferencia ya mencionada entre la estructura turística existente en las poblaciones de sotavento y las del resto de la isla.

Así, el primer eje señala que siguen apareciendo las diferencias que apuntan hacia dos tipos de grupos de actores: aquellos que se orientan más hacia actividades tradicionales, donde podría incluirse la forma local de hacer uso de la playa (valores pequeños en Eje 1, Tabla 4) y los que apuntan más a aspectos más relacionados con actividades de corte cultural o natural más especialmente turísticas (valores altos en Eje 1, Tabla 4). Esto es así porque la práctica autóctona de la playa puede considerarse que tiene connotaciones tradicionales.

La complementariedad de las actividades productivas tradicionales de Fuerteventura marcaba un periodo de reunión social en determinados lugares costeros donde se trasladaba en casetas la mayor parte de la comunidad y pasaba a dedicarse principalmente a la pesca y al marisqueo. Este espacio, separado de espacio habitual, se constituía como una extensión del pueblo donde las relaciones sociales se orientaban en mayor medida hacia el ocio. Estas concentraciones suponen importantes espacios de interacción, socialización y transmisión cultural. En la actualidad, estas características, observadas durante la fase de trabajo de campo, se corresponden en gran medida con el extremo inferior del primer eje del análisis realizado (valores pequeños en Eje 1, Tabla 4), donde además de la playa destacan las prácticas relacionadas con las fiestas tradicionales, la gastronomía, la pesca y el camping. Frente a este grupo se encuentran aquellos que se relacionan con prácticas de corte cultural (foto y video de la naturaleza o en general, deportes acuáticos, rutas urbanas y ciclos culturales y conferencias).

Esta tendencia queda complementada a partir de los resultados del segundo eje generado, según el cual otra forma de ordenar la población local de Fuerteventura es en función de la vinculación de las actividades que se realizan con el medio. Así, por un lado encontramos aquellos que realizan prácticas relacionadas con un tipo de ocio más vinculado a la naturaleza (observación de fauna y vegetación, contemplación de la naturaleza, foto y video de la naturaleza o general, etc.), mientras por el otro se sitúan aquellas personas que se caracterizan por la realización de actividades más festivas (discotecas, clubes nocturnos, bares o espectáculos y conciertos, además de camping o deportes tradicionales). Esta diferenciación es muy similar a aquella resultante de la ordenación del grupo de turistas ya vista (Eje 2, Tabla 3), sin embargo, respecto a la población local encontramos que, si bien es clara la contraposición entre personas que realizan prácticas más relacionadas con la naturaleza y aquellas entre las que priman las actividades de corte más lúdico, determinadas actividades ociosas tradicionales siguen estando presentes y la caracterización de prácticas de corte más impersonal y desvinculadas del medio no llega a darse. 
Tabla 4. Pesos de las variables sobre las principales actividades realizadas por el grupo de población local en Fuerteventura en los dos primeros ejes del análisis de ordenación. Se representan sólo las variables de mayores pesos positivos y negativos.

\begin{tabular}{|c|c|c|c|}
\hline VARIABLE & F1 & VARIABLE & F2 \\
\hline Foto, video naturaleza & 1,345 & Observación fauna & 2,085 \\
\hline Foto, video general & 1,274 & Observación vegetación & 2,077 \\
\hline Deportes acuáticos & 1,211 & \begin{tabular}{|l|}
$\begin{array}{l}\text { Contemplación } \\
\text { naturaleza }\end{array}$ \\
\end{tabular} & 1,379 \\
\hline Rutas urbanas & 1,123 & Foto, video naturaleza & 1,160 \\
\hline $\begin{array}{l}\text { Pesca recreativa de } \\
\text { barco }\end{array}$ & 1,079 & Foto, video general & 0,570 \\
\hline $\begin{array}{l}\text { Ciclos culturales, } \\
\text { conferencias }\end{array}$ & 1,033 & Interacción con turistas & 0,234 \\
\hline \multicolumn{2}{|l|}{$* * *$} & \multicolumn{2}{|l|}{$* * *$} \\
\hline Senderismo & 0,515 & Espectáculos, conciertos & $-0,367$ \\
\hline Gastronomía local & 0,447 & \begin{tabular}{|l|} 
Participación en deportes \\
tradicionales
\end{tabular} & $-0,419$ \\
\hline $\begin{array}{l}\text { Participación en fiestas } \\
\text { tradicionales }\end{array}$ & 0,366 & Camping & $-0,505$ \\
\hline $\begin{array}{l}\text { Observación de fiestas } \\
\text { tradicionales }\end{array}$ & 0,273 & Clubes nocturnos, bares & $-0,642$ \\
\hline Playa & 0,161 & Discotecas & $-0,836$ \\
\hline \multicolumn{2}{|c|}{ F1 (18,10 absorbed variance) } & \multicolumn{2}{|c|}{ F2 (10,40 absorbed variance) } \\
\hline
\end{tabular}

\section{CONCLUSIÓN}

El proceso de diferenciación como destino de Fuerteventura se basa en una paulatina introducción del matiz de la sostenibilidad y la conservación. Los procesos de creación de imágenes acordes con estos discursos y su creciente patrimonialización de espacios y actividades se orientan hacia un modelo turístico que incorpore a la oferta tradicional de sol y playa otros elementos relacionados con la naturaleza y cultura locales. Concretamente, la imagen proyectada por las administraciones muestra la isla como un espacio donde consumir espacios naturales, elementos culturales concebidos de manera estática (artesanías, molinos reformados o platos típicos, además de museos, exposiciones o monumentos) y playas turísticas.

Estas dinámicas de renovación implican unos procesos de selección y resignificación territorial que suelen obviar las simbolizaciones autóctonas derivadas de la cotidianidad (Carrier y West, 2009; Chatty y Colchester, 2002; Escalera, 1993; Coca, 2008). La posible discordancia entre las imágenes proyectadas y las imágenes propias de las poblaciones locales suele conllevar efectos socioecológicos imprevistos de variado alcance. 
En este trabajo se ha analizado cómo los procesos de implementación de estrategias de diferenciación turística de Fuerteventura se basan en las actividades cotidianas de las poblaciones locales, elemento fundamental de su imagen propia, o por el contrario están basadas y orientadas hacia un consumidor exógeno.

A partir de los análisis realizados se ha mostrado que la población presente en Fuerteventura puede ordenarse en función de la regularidad del tipo de actividades que realiza, donde las más habituales son aquellas relacionadas con prácticas vinculadas al ocio de sol y playa, y las menos comunes las vinculadas a la realización de actos de desarrollo cultural-educativo. Además, puede decirse que existen dos tipos diferenciados de usuarios, aquellos que llevan a cabo actividades con base en la naturaleza (en gran medida turistas), frente a los que realizan actividades con base en la cultura (locales) (Tabla 5).

Tabla 5. Formas de ordenar la población de Fuerteventura en función de las prácticas realizadas.

\begin{tabular}{|l|c|c|}
\hline \multirow{2}{*}{$\begin{array}{l}\text { Población } \\
\text { indiferenciada }\end{array}$} & Regularidad de actividades & Contraste entre actividades \\
\cline { 2 - 3 } & Sol y Playa & Naturaleza (turistas) \\
\hline \multirow{3}{*}{ Turistas } & Culturales-instructivas & Cultura (locales) \\
\hline \multirow{2}{*}{ Locales } & Sol y Playa & $\begin{array}{c}\text { Cultural vinculado al } \\
\text { entorno }\end{array}$ \\
\cline { 2 - 3 } & Naturaleza y Cultura & Lúdicas desvinculadas \\
\cline { 2 - 3 } & Tradición & Naturaleza \\
\hline
\end{tabular}

Una interpretación más particularizada muestra que los turistas que visitan la isla realizan fundamentalmente actividades relacionadas con el turismo tradicional de sol y playa, mientras que los pobladores locales se centran en aquellas que tienen que ver con su cultura y tradición (entre las que encajarían determinadas actividades relacionadas con el sol y la playa). Ambos grupos también realizan actividades acordes con un turismo con base en la cultura y la naturaleza, pero en mucha menor medida y relegadas a un segundo plano. En todo caso, aquellos usuarios locales o turistas que llevan a cabo este tipo de actividades secundarias, contrastan con otro grupo diferenciado de agentes, presente en ambos grupos de usuarios, para quienes la naturaleza y la cultura carecen de interés y centran su atención sobre actividades de corte lúdico y festivo.

Teniendo en cuenta que el modelo turístico de Fuerteventura, dadas sus características, ha sido siempre el tradicional de sol y playa, y que desde sus inicios su imagen turística ha venido siendo asociada al estereotipo que marca este tipo de oferta, parece normal que estos elementos se constituyan aún como las principales motivaciones a la hora de visitar la isla. La tendencia a la renovación de la imagen actual se basa en la tendencia 
a la rentabilización de determinados bienes presentes en el resto de la isla. Este proceso implica la selección de unos bienes frente a otros con la intención de generar una imagen cultural concreta del destino.

Fundamentalmente, los elementos elegidos para proyectar esta imagen son aquellos relacionados con la naturaleza y la cultura. En un primer acercamiento podría parecer que esta selección se fundamenta sobre la forma particular de las poblaciones locales de concebirse a sí mismos y a su entorno, si observamos que las principales prácticas culturales de los pobladores nativos de la isla son aquellas relacionadas con la tradición, la cultura y la naturaleza. No obstante, el proceso de selección, diseño y puesta en uso de las imágenes proyectadas implican a su vez un proceso de resimbolización que, en este caso, poco tiene que ver con las significaciones autóctonas.

Así, la 'naturaleza' y la 'cultura', entendidas como un proceso dinámico en donde se van generando las significaciones propias a partir de prácticas consuetudinarias, son presentadas a partir de su proyección mercantil como elementos estáticos destinados al consumo de los visitantes. A partir de la evidencia de que la población turista concibe ciertas partes y actividades presentes en la isla ('naturaleza' y 'cultura') como complementarias a los productos de sol y playa, los esfuerzos por desarrollar otro tipo de imagen se han centrado en potenciar dichos atributos a partir de su patrimonialización. El resultado de este proceso implica una congelación de determinados rasgos 'naturales', 'históricos' o 'culturales' susceptibles de ser consumidos. Determinadas naturalezas pasarán a engrosar la lista de espacios protegidos, así como determinados artefactos y actividades se cristalizarán en museos, exposiciones, convertidas en elementos para la contemplación a los que se les otorga esencialmente un papel estético. 


\section{REFERENCIAS BIBLIOGRÁFICAS}

BELL, S. (2001) "Landscape pattern, perception and visualization in the visual management of forests". Lanscape and Urban Planning. 54. pp. 201-211.

BUTLER, RICHARD W. (1980) “The concept of a tourist area cycle evolution: Implications for management of resources". Canadian Geographer. 25(1): 5-12.

BUTLER, RICHARD W. (1994) “The Thin Edge of the Wedge”. En Valene Smith y William Eadington, Alternatives tourism. John Wiley \& sons: Chichester. Cánoves, G., HERRERA, L. \& VILLARINO, M. (2005) “Turismo rural en España: paisajes y usuarios, nuevos usos y nuevas visiones. Cuadernos de Turismo. 15: 63-76.

CARRIER, J. \& WEST, P. (2009) "Introduction: Surroundings, Selves and Others: The Political Economy of Environment and Identity”. Landscape Research. 34(2): 157-170.

CATER, E. y LOWMAN, G. (Eds.) (1994) Ecotourism: A sustainable option? Chichester UK: John Wiley \& Sons.

CHAMBERS, E. (Ed.) (1997) Tourism and culture. An applied perspective. Albany, USA: State University of New York.

CHATTY, D. \& COLCHESTER, M. (Eds.) (2002) Conservation and mobile indigenous peoples: Displacemente, forced settlement and sustainable development. Oxford \& New York, Berghahn Press.

COCA, A. (2008) Los Camperos. Territorios, usos sociales y percepciones en un espacio natural andaluz. Sevilla, Fundación Blas Infante.

CRAIK, J. (1997) “The culture of tourism”. In: Rojek C and Urry J. Touring Cultures. London, New York: Routledge, 1997, p. 113 - 136.

DÍAZ RODRÍGUEZ, P., RUIZ-LABOURDETTE, D., RODRÍGUEZ, A.J., SANTANA, A., SCHMITZ, M. \& PINEDA, F.D (2010a) "Landscape perception of local population. Relationship between ecological characteristics, local society and visitor preferences". En C.A. Brebbia \& F.D. Pineda (Eds.) Sustainable Tourism IV. Southampton, UK, WIT Press. pp.309-317.

DÍAZ RODRÍGUEZ, P., SANTANA TALAVERA, A. \& RODRÍGUEZ DARIAS, A.J. (2010b) "Implicaciones del ritmo de crecimiento e influencia turística en la valoración del paisaje y el desarrollo turístico. El caso de Fuerteventura (Islas Canarias, España)”. Gaudeamus: Hospitalidad y Sostenibilidad (En prensa).

ESCALERA REYES, F.J. (1993) “Espacios naturales-Espacios sociales. Por un tratamiento integral del Patrimonio Ecológico-Cultural de Andalucía. El caso del Parque Natural de la Sierra de Arecena y Picos de Aroche (Huelva)". En I. González Turmo (Ed.) Parques Naturales Andaluces. Conservación y cultura. Gabinete de Divulgación y Comunicación 
Social de la Agencia de Medio Ambiente, Junta de Andalucía, pp. 11-17.

FRANKLIN, A. y CRANG, M. (2001) “The trouble with tourism and travel theory?". Tourist Estudies. 1 (1): 5-22.

FRANKLIN, A. y CRANG, M. (2001) “The trouble with tourism and travel theory?" Tourist Studies, 1(1): 5-22.

GALANI-MOUTAFI, V. (2000) “The self and the other - Traveler, ethnographer, tourist". Annals of Tourism Research, 27(1): 203-224.

HANNERZ, U. (1996) Conexiones transnacionales. Cultura, gente, lugares. Madrid: Cátedra, 1996.

HARKIN, M. (1995) "Modernist anthropology and tourism of the authentic". Annals of Tourism Research, 22(3): 650-670.

JUlES-ROSETTE, B. (1994) “Black Paris. Touristic simulations”. Annals of Tourism Research, 21(4): 679-700.

MARKWELL, K. (2001) "'An intimate rendezvous with nature? Mediating the touristnature experience at three tourist sites in Borneo". Tourist Studies, 1(1): 39-58

NURYANTI, W. (1996) “Heritage and postmodern tourism”. Annals of Tourism Research, 23(2): 249-260.

PICARD, M. y WOOD, R.E. (Eds.) (1997) Tourism, ethnicity and the state in Asian and Pacific societies. Honolulu: University of Hawai'i Press.

PRETES, M. (1995) “Postmodern tourism. The Santa Claus Industry”. Annals of Tourism Research, 22(1): 1-15.

RODRÍGUEZ DARIAS, AL.J., DÍAZ RODRÍGUEZ, P., RUIZ-LABOURDETTE, D., PINEDA, F.D., SCHMNITZ, M. \& SANTANA TALAVERA, A. (2010) "Selection, design and dissemination of Fuerteventura's projected tourism image (Canary Isles)". En S. Favro \& C.A. Brebbia (Eds.). Island Sustainability. Southampton and Boston, WIT Press, pp, 13-24.

RUIZ-LABOURDETTE, D., DÍAZ RODRÍGUEZ, P., RODRÍGUEZ DARIAS, A.J., SANTANA, A., SCHMITZ, M. \& PINEDA, F.D. (2010) "Scales and scenarios of change in the anthropology-landscape relationship: models of cultural tourism in Fuerteventura (Canary Isles)". En S. Favro \& C.A. Brebbia (Eds.). Island Sustainability. Southampton and Boston, WIT Press, pp: 51-64.

SANTANA TALAVERA, A. (2009) Antropología do turismo. Analogias, encontros e relaçoes. Sao Paulo, Aleph. 
SANTANA TALAVERA, A., RODRÍGUEZ DARIAS, A.J., DÍAZ RODRÍGUEZ, P. \& RAMOS, A.R. (2010a) "Innovación con compromisos. Retos en la renovación de la imagen en destinos turísticos maduros (Fuerteventura, Islas Canarias)”. En R. Hernández Martín \& A. Santana Talavera (Eds.). Destinos maduros ante el cambio. Reflexiones desde Canarias. Tenerife, Instituto Universitario de Ciencias Políticas y Sociales, Universidad de La Laguna, pp. 137-156.

SANTANA, A., RODRÍGUEZ, A.J. \& DÍAZ, P. 2010. Projected Image and Correlation of Interests on the Island of Fuerteventura (Canary Islands, Spain). Asian Journal of Tourism and Hospitality Research. 4(1). En prensa.

SANTANA, A., RODRÍGUEZ, A.J., DÍAZ, P. \& AGUILERA, L. (2010b) "Facebook, heritage and tourism reorientation. The cases of Tenerife and Fuerteventura (Canary isles, Spain)". International Journal of Web Based Communities (IJWBC). 8(1). En Prensa.

SELWYN, TOM (1990) “Tourist brochures as post-modern myths”. Problems of tourism, 13(3-4): 13-25.

SMITH, V.L. Y EADINGTON, W.R. (Eds.) (1994) Tourism alternatives: Potentials and problems in the development of tourism. Chichester UK: John Wiley \& Sons.

SMITH, VALENE L. Y BRENT, MARYANN (Eds.) (2001) Hosts and guests revisited: Tourism issues of the 21st century. New York: Cognizant Communication.

TUCKER, H. (2001) “Tourists and troglodytes - Negotiating for sustainability”. Annals of Tourism Research, 28(4): 868-891.

VALCUENDE DEL RÍO, J.M. (2004) Aproximaciones antropológicas al medio ambiente. Revista Cabeza de Gallo. 14:77-95.

WANG, NING (1999) "Rethinking authenticity in tourism experience". Annals of Tourism Research, 26(2): 349-370. 